\title{
4 ENSAIOS PARA HOMEÓSTATOS VISUAIS
}

Fernando Aguiar

RESUMO: Releituras dos Homeóstatos de José-Alberto Marques.

PALAVRAS-CHAVE: Homeóstatos. José-Alberto Marques. Poesia Experimental Portuguesa. Releitura.

${ }^{*}$ Poeta. Lisboa, Portugal. E-mail: fernandoaguiar@netcabo.pt

Esta obra está licenciada com uma licença Creative Commons.

Texto Digital, Florianópolis, Santa Catarina, Brasil, v. 12, n. 1, p. 165-170, jan./jun. 2016. ISSNe: 1807-9288. 
Fig. 1 - "A Noite Acontece" (Ensaio para Homeóstato Visual \# 1) [Fita adesiva e Letter-Press sobre papel Cotman $425 \mathrm{gr}$. | 76x56 cm | 2015]

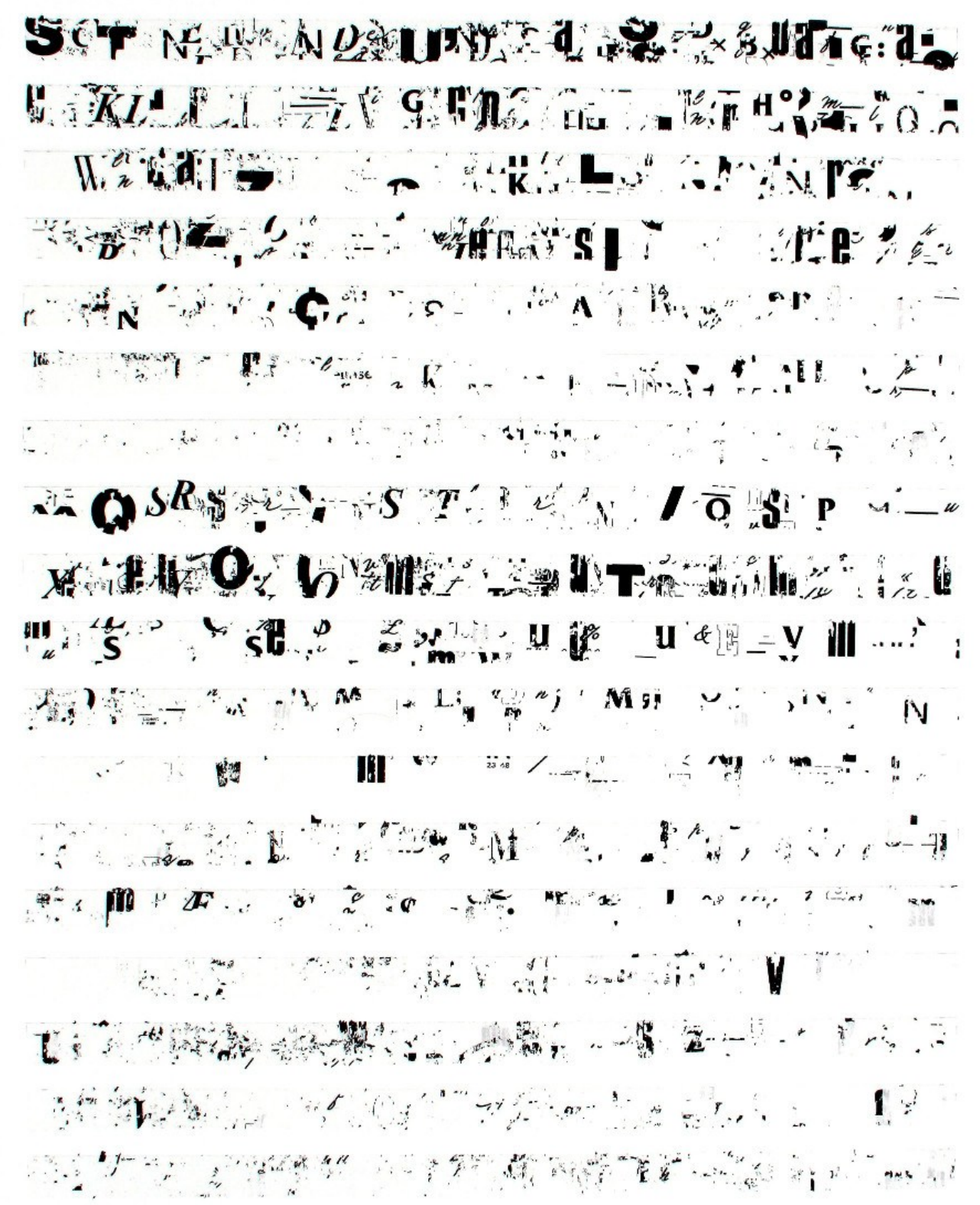


Fig. 2 - "Sonhos de Lume" (Ensaio para Homeóstato Visual \# 2) [Fita adesiva e Letter-Press sobre papel Cotman 425 gr. | 76x56 cm | 2015]

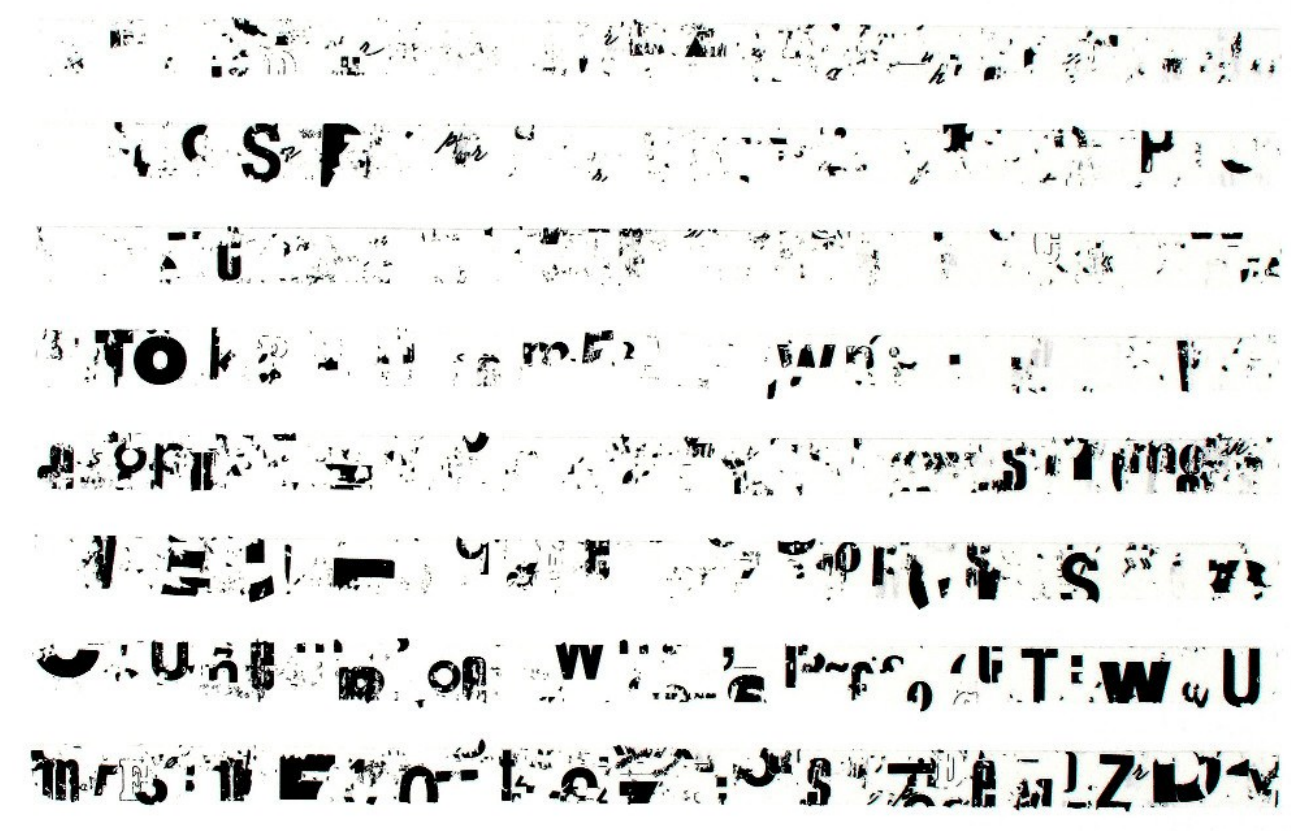


Fig. 3 - "Teu Nome" (Ensaio para Homeóstato Visual \# 3) [Fita adesiva e Letter-Press sobre papel Cotman 425 gr. | $76 \times 56 \mathrm{~cm}$ | 2015]

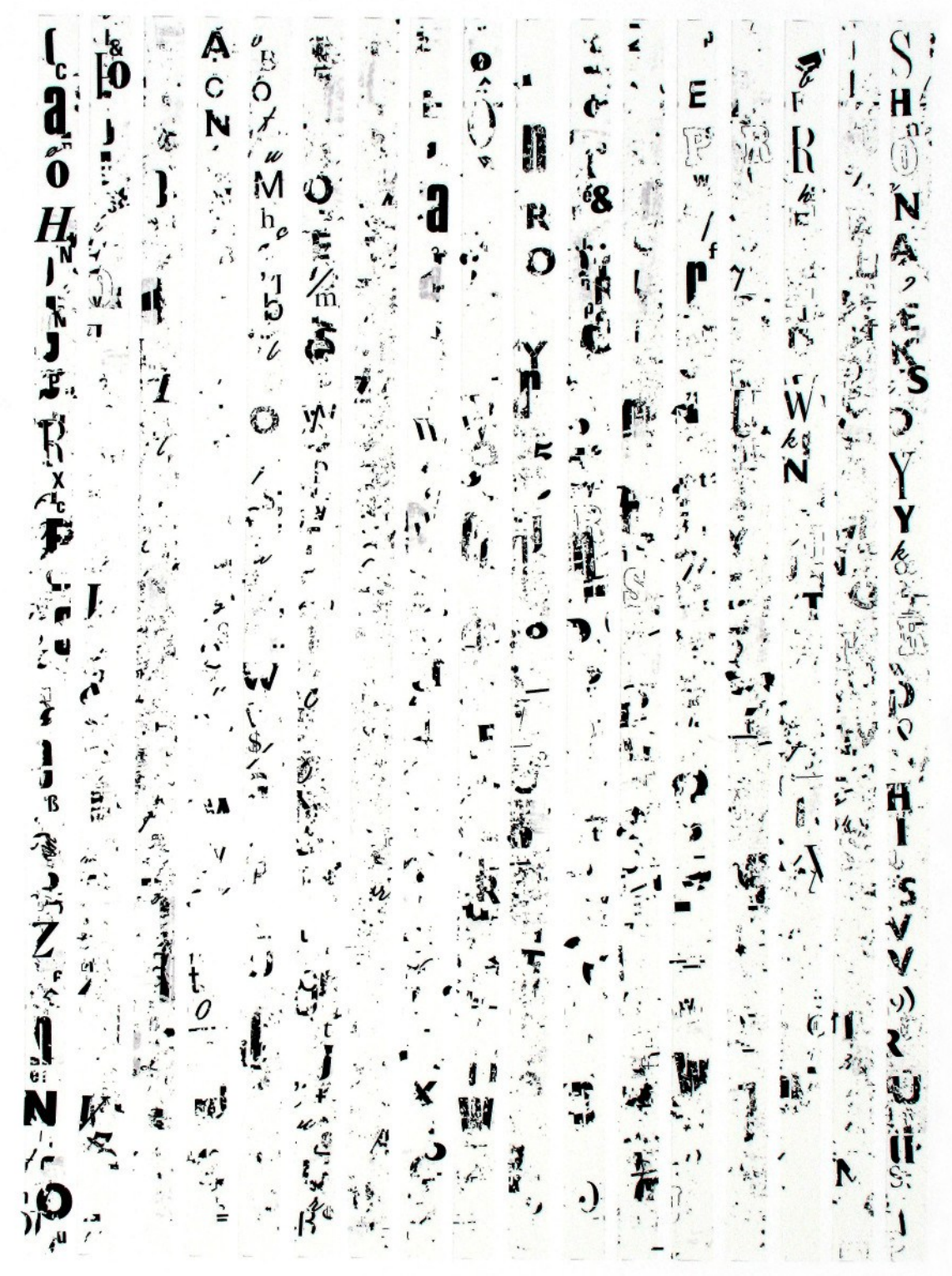


Fig. 4 - "Vento: Amor e Liberdade" (Ensaio para Homeóstato Visual \# 4) [Fita adesiva e Letter-Press sobre papel Cotman $425 \mathrm{gr}$. | $76 \times 56 \mathrm{~cm}$ | 2015]

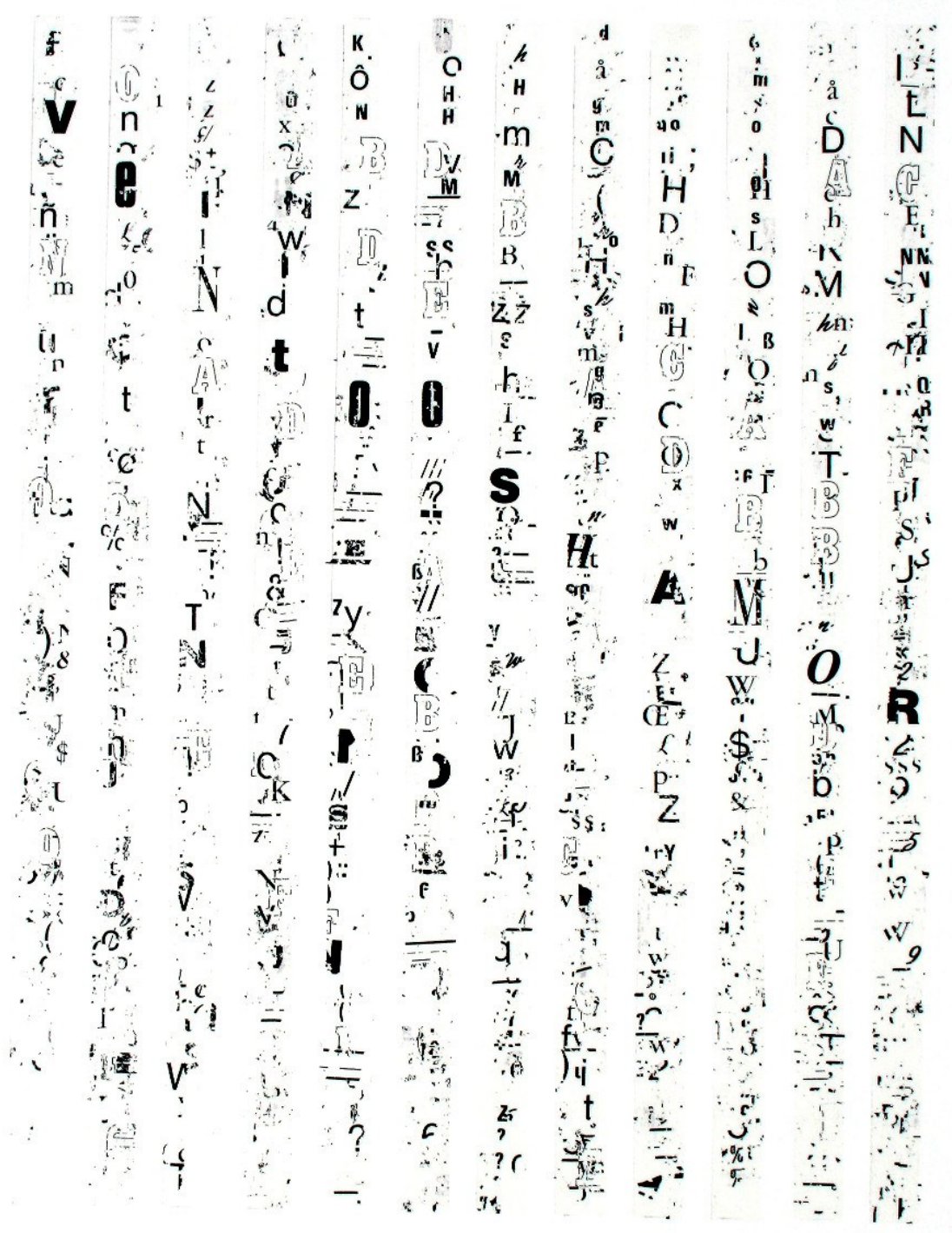




\section{ESSAYS FOR VISUAL HOMEOSTATS}

ABSTRACT: Re-readings of José-Alberto Marques' Homeóstatos.

KEYWORDS: Homeóstatos. José-Alberto Marques. Portuguese Experimental Poetry. Re-readings. 